$\begin{array}{ll} & \text { Etnográfica } \\ \text { etnográfica } & \text { Revista do Centro em Rede de Investigação em }\end{array}$

Antropologia

vol. $26(1) \mid 2022$

Vol. 26 (1)

\title{
La economía de autos robados en São Paulo: mirada etnográfica sobre la reproducción de desigualdades y violencia en América Latina
}

The economy of stolen cars in São Paulo: an ethnographic look at the reproduction of inequalities and violence in Latin America

\section{Gabriel Feltran y Janaina Maldonado}

\section{QpenEdition}

\section{Journals}

Edición electrónica

URL: https://journals.openedition.org/etnografica/11311

DOI: 10.4000/etnografica.11311

ISSN: 2182-2891

\section{Editor}

Centro em Rede de Investigação em Antropologia

Edición impresa

Paginación: 125-148

ISSN: 0873-6561

\section{Referencia electrónica}

Gabriel Feltran y Janaina Maldonado, «La economía de autos robados en São Paulo: mirada etnográfica sobre la reproducción de desigualdades y violencia en América Latina», Etnográfica [En línea], vol. 26 (1) | 2022, Publicado el 25 febrero 2022, consultado el 30 junio 2022. URL: http:// journals.openedition.org/etnografica/11311; DOI: https://doi.org/10.4000/etnografica.11311

\section{(ब) $(1) \Theta$}

Etnográfica is licensed under a Creative Commons Attribution-NonCommercial 4.0 International License. 


\section{La economía de autos robados en São Paulo: mirada etnográfica sobre la reproducción de desigualdades y violencia en América Latina}

\section{Gabriel Feltran y Janaina Maldonado}

En Brasil, cerca de 500 mil vehículos son robados todos los años, siendo un 45\% en São Paulo. En el caso de los autos, los destinos son conocidos - deshuesaderos, negocios de autopartes, fronteras, subastas, reventa, usos en otras acciones delictivas. Este artículo traza la trayectoria de un Ford Ka 2018 robado y desarmado en São Paulo y debate la regulación de las economías ilegales. Aprenderemos que efectos el dinero de las economías ilegales tiene en las legales, pero también en la dinámica de reproducción política de las desigualdades y de la violencia urbana en São Paulo. El artículo está basado en una etnografía multi-situada, colectiva, desarrollada en Brasil entre 2015-2020.

PALABRAS CLAVE: mercados ilegales, desigualdades, autos, mecanismos, São Paulo.

The economy of stolen cars in São Paulo: an ethnographic look at the reproduction of inequalities and violence in Latin America - In Brazil, around 500,000 vehicles are stolen every year, 45\% of them in São Paulo. In the case of cars, the destinations are well known - junkyards, auto parts shops, borders, auctions, resale, and uses in other criminal activities. This article traces the trajectory of a stolen and dismantled 2018 Ford Ka in São Paulo and debates the regulation of illegal economies. We will learn what effects the money from illegal economies has on the legal ones, but also on the dynamics of political reproduction of inequalities and urban violence in São Paulo. The article is based on a multi-sited, collective ethnography developed in Brazil from 2015-2020.

KEYWORDS: illegal markets, inequalities, cars, mechanisms, São Paulo.

FELTRAN, Gabriel (gabrielfeltran@gmail.com) - profesor del departamento de Sociología de la Universidad Federal de San Carlos; investigador del Centro Brasileiro de Análise e Planejamento (Cebrap). São Paulo, Brasil.

MALDONADO, Janaina (janamaldonado40@gmail.com) - investigador de doctorado en el Instituto Alemán de Estudios Globales y de Área (GIGA); doctorando en la Escuela de Postgrado "Democratización de la Seguridad en Tiempos Turbulentos" de la Universidad de Hamburgo, Alemania. 


\section{INTRODUCCIÓN}

La metrópoli de São Paulo tiene 21 millones de personas y sus distritos más pobres tienen una esperanza de vida de 57 años de edad, mientras que las personas más ricas viven 80 años (Rede Brasil Atual 2019). Los ricos viven, en promedio, 23 años más que los pobres en la ciudad que alberga un tercio del producto interno bruto de Brasil. Los mecanismos de reproducción de estas desigualdades, que hoy en día ocupan simultáneamente las clasificaciones más dispares de pobreza y riqueza global en São Paulo, todavía deben entenderse mejor. Como en muchas otras ciudades latinoamericanas, en São Paulo las desigualdades también se manifiestan - aunque no directamente - en forma de violencia (Fischer, McCann y Auyero 2014).

El crimen violento y el debate sobre el delito, a su vez, alimenta la representación, compartida entre las élites y los trabajadores, de la "violencia urbana" (L. Silva 2010; Kessler 2011). ${ }^{1}$ El mundo del crimen de São Paulo se organiza desde los 1990 en el ritmo de una gran facción criminal hegemónica, el PCC (Primer Comando de la Capital) cuyas redes son globales (Feltran 2020, 20 16; Willis 2015). El PCC actúa como una masonería del crimen, con emprendedores autónomos y sin caja único (Feltran 2018). Es más que nada un regulador del mercado, lo que se hace con posibilidad de recurso a la fuerza armada, pero en las rutinas evitando al máximo utilizarla. Un recorrido por los mercados (i)legales de automóviles será nuestro instrumento empírico acá para comprender la reproducción de las desigualdades y la violencia en São Paulo. ${ }^{2}$

La década de 1990 vio una explosión de crímenes violentos en la ciudad (Caldeira 2000; Hirata 2018; Feltran 2011), mientras que la década de 2000 vio la consolidación de la hegemonía del PCC en las periferias, que estableció el orden en el universo criminal local (Biondi 2018; Manso y Dias 2018; Feltran 2018). En las regiones centrales de la ciudad, la seguridad privada se consolidó y la policía militar se tornó más rica y más fuerte (Telles 2010; Feltran 2011; Hirata 2018). Las redes de metro y tren metropolitano de la ciudad

l Desde la década de 1960 Machado da Silva ha argumentado que la violencia urbana es una representación pública que, en el debate público brasileño, involucra procesos empíricos muy diferentes (tráfico de drogas, violencia doméstica, la implementación de políticas de seguridad, armas, pobreza, negrura, masculinidad, etc.). Afirma que a pesar de su familiaridad intuitiva, debemos evitar dar por sentado el concepto de "violencia urbana". Por el contrario, debemos desenredar empíricamente la caja negra de las rutinas concretas de la vida urbana para desenmascarar la violencia urbana no como un concepto sino como un objeto para ser entendido (L. Silva 2008, 2016). Michel Misse $(2010,2018)$ e Inverses Collectif (2016) se desarrollaron aún más, yendo más allá de las interpretaciones más culturalistas de Caldeira (2000) y Holston (2009) de la política, la violencia y la ciudad en el contexto brasileño.

2 Los autores agradecen a Luana Motta, Deborah Fromm, André de Pieri Pimentel, Isabela Pinho, Lucas Alves, Juliana Alcantara y Luiz Gustavo Pereira que conforman el equipo de investigación del proyecto Fapesp (2013/07616-7) del que se ha derivado el presente artículo. 
se han modernizado y ampliado significativamente desde la década de 2000 (Requena 2019) y son mucho más seguras en 2020 que en la década de 1990 (J. Silva 2017). A pesar de esto, los paulistanos consideran que los autobuses, trenes y trenes subterráneos son mucho menos eficientes que sus automóviles privados. El transporte público es además muy caro. Para darle una idea, un trabajador que realiza solo dos viajes al día en São Paulo, en autobús o metro, habrá gastado $0,24 \mathrm{SM}$ a finales del mes. ${ }^{3}$ Para muchas personas, esto representa una cuarta parte de sus ingresos mensuales. ${ }^{4}$

Por lo tanto, la mayoría de los paulistanos viven con muy poca movilidad. En la gran São Paulo global, no todos se mueven (Freire-Medeiros 2009; Urry 2004; Dennis y Urry 2009). Todavía es común, en la investigación de campo, encontrarse con residentes de las periferias que nunca, o muy raramente, abandonaron sus vecindarios. En cualquier caso, para aquellos que no viven en el centro de la ciudad y necesitan moverse, el automóvil privado y, más recientemente, las aplicaciones Uber y análogas son casi siempre las alternativas más rápidas, prácticas y seguras. Por esta razón, el tráfico en São Paulo es infernal: los promedios de $100 \mathrm{~km}$ de carreteras congestionadas entre semana son muy comunes.

Además de la practicidad, hay condiciones objetivas que le dan al automóvil un inmenso poder simbólico. A diferencia de otros países de América del Norte y del Sur, los automóviles son extremadamente caros en Brasil. Un Toyota Corolla 2018 cuesta un promedio de 18.000 doláres en los EE.UU. (13,8 SM estadunidenses). En Brasil, el mismo automóvil cuesta un promedio de USD 23.000 (92,5 SM brasileños). En términos relativos, el automóvil brasileño es casi siete veces más caro. Las clases medias y las élites eran, hasta la década de 2000, las únicas capaces de moverse por la ciudad en coche. ${ }^{5}$ Por lo tanto, los automóviles se han convertido en potentes signos de diferenciación social y autonomía en Brasil, como en otros contextos de América del Norte y del

3 A lo largo del artículo utilizaremos el acrónimo SM para salario mínimo. Todos los precios se ajustaron al salario mínimo considerando USD 1,00 = BRL 4,00 (promedio de 2010) y el salario mínimo nacional de BRL 1000,00 (o USD 250,00) en valores 2020. Es importante recordar que el valor real del salario mínimo brasileño aumentó en un 75\% entre 2004 y 2019 (G1 2019, disponible en https:// gl.globo.com/economia/noticia/2019/04/15/veja-historico-dos-ultimos-reajustes-do-salario-minimo .ghtml - última consultación en enero 2022).

4 Un boleto individual de metro o autobús cuesta 0,004 SM. No hay planes semanales o mensuales que puedan reducir el costo, aunque bilhete único, los boletos, que permiten transferencias gratuitas de tren, metro y autobús en un solo viaje, están disponibles. En 2018, seis de cada diez trabajadores brasileños ganaron el salario mínimo mensual (Agência O Globo 2019).

5 La democratización de los automóviles en la ciudad durante los últimos 20 años se debe al dinamismo del mercado informal de automóviles usados y autopartes y, lo que es más importante, a la expansión del crédito a los que generan menos ingresos durante los gobiernos de Lula (2002- 2010). Este fenómeno, como un efecto secundario directo, o incluso como un elemento fundamental, condujo a un aumento relacionado en robos de vehículos y anillos de robo de vehículos. 
Sur (Miller 2001). Hasta el día de hoy, las élites de São Paulo se desplazan casi exclusivamente en automóvil y casi nunca van a las periferias, excepto cuando viven en comunidades cerradas ricas, algunas de las cuales se encuentran lejos del centro de la ciudad.

En las últimas décadas, el dinero de los mercados ilegales ha sido muy relevante para las rutinas de las periferias (Feltran 2011, 2018), ha producido territorios (Batista 2015) y ha modificado el paisaje urbano (Caldeira 2000), además de producir imágenes de violencia global (Cohen 2017). Asumimos acá que la economía urbana transnacional altamente desigual produce y es producida por las rutinas de la vida cotidiana (Knowles 2015; Tsing 2005; Simone 2004; Feltran 2020). Robos de autos son rutina en São Paulo.

Desde el momento en que se roba un automóvil, muchas personas comienzan a ganar dinero en proporciones desiguales. Al seguir los autos, aprenderemos dónde circula este dinero y qué efectos tiene en las economías legales e ilegales, pero también en los mecanismos de reproducción de las desigualdades y la violencia urbana. Nos llevó un tiempo comprender que el robo local de automóviles estaba alimentando los mercados mundiales. No teníamos ni idea de la magnitud del mercado ilegal de automóviles, ni la escala de los mercados de autopartes y accesorios hasta una parte de nuestra investigación que se desarrolló en Europa (específicamente Berlín, Londres y París) en el transcurso de varios meses en 2017 y 2019. Europa es quizás el continente menos enamorado de la cultura del automóvil (Miller 2001) pero todavía circula allá mucho dinero generado por vehículos latinoamericanos robados. Eso porque el cambio de autos robados por cocaína genera ganancias increíbles que son trasladadas al exterior con la exportación de la droga y por el consumo (Feltran 2019). El comercio legal vibrante insinúa el comercio igualmente vibrante del mercado ilegal entre diferentes países (Sandoval Hernández 2005, 2012).

Nuestra investigación nos ha enseñado que, a pesar de la existencia de itinerarios clásicos seguidos por vehículos robados, la característica distintiva de los mercados legales es su naturaleza perennemente improvisada y circunstancial. En tal caso, se requiere un método, sin caricaturizar estos mercados o tratar sus mecanismos operativos en abstracto; decidimos una investigación etnográfica multi-situada, del tipo que sigue objetos y reconstruye viajes típicos. Además, es necesario repensar la teoría para comprender las operaciones de estos mecanismos y sus efectos contemporáneos según las escalas apropiadas. Decidimos, desde el punto de vista teórico, la tradición en el pensamiento político latinoamericano que reconoce una pluralidad de órdenes, además de la del Estado, que gobiernan la vida urbana marginal.

Sin tener en cuenta las órdenes urbanas plurales que rigen los mercados ilegales, los autores tienden a leer los circuitos sociales de una manera deductiva 
y verlos como resultado de neoliberalismo o desarrollo incompleto. ${ }^{6}$ Tales enfoques deductivos y normativos a menudo no entienden las desigualdades dentro de las grandes ciudades, ya que los datos agregados tienden a ocultar el hecho de que la esperanza de vida en el barrio más rico de São Paulo tiene aproximadamente 79 años, mientras que en promedio las personas viven solo 55 años en los más pobres distritos. Por otro lado, importantes estudios etnográficos sobre mercados informales en África, desde Keith Hart (1973) hasta Jane Guyer $(1995,2004)$, han ayudado a contrarrestar tales argumentos normativos, a pesar de haber tocado apenas "el mundo del crimen" como régimen normativo. No obstante, la literatura aún carece de trabajo empírico inductivo que pueda mejorar nuestra comprensión de este fenómeno contemporáneo, que está presente en todas las ciudades principales.

Contrariamente a las teorías normativas, los trabajos empíricos recientes han puesto de manifiesto el hecho de que es perfectamente posible que el desarrollo económico y las comunidades cerradas coexistan con diversas formas de informalidad urbana, ilegalidad y delitos violentos (Rabossi 2008; Sandoval Hernández 2005, 2008; Hirata 2018; Feltran 2018). La literatura ya ha declarado que no hay una frontera clara entre la ciudad "legal" y la "ilegal" (Telles 2013), pero la falta de nitidez no es lo mismo que la indeterminación (Simmel 2004 [1900]). En São Paulo existe una distinción práctica relevante entre personas, territorios y bienes considerados legales o ilegales (Misse 2005). Esta línea de distinción a menudo es una división entre la vida y la muerte: la letalidad policial dirigida a "ladrones" representa hasta el 25\% de la tasa de homicidios en el estado de São Paulo, y hasta el 40\% en el estado de Río de Janeiro en 2019.7

Estudiar la vida social de los objetos es una tradición metodológica bien establecida en las ciencias sociales (Appadurai 1986; Freire-Medeiros e Menezes 2016; Henare, Holbraad y Wastell 2007; Kopytoff 2014; Miller 2001; Mintz 2003; Knowles 2014; Latour 2005). Pero métodos similares también se usan fuera de la academia: "seguir el dinero", por ejemplo, es una de las formas más establecidas en las investigaciones policiales que estudian el funcionamiento de redes complejas de crimen organizado. ${ }^{8}$ Recientemente, trabajos seminales como los de Knowles (2014) y Tsing (2015) han llevado esta tradición a una escala transnacional y han innovado teóricamente al enfocarse no solo

6 Los estudios de Loïc Wacquant (Wacquant 1996, 2009; Wacquant y Howe 2008) sobre la marginalidad avanzada y el estado penal son ejemplos de este enfoque normativo y muy influyentes dentro de esta literatura.

7 Defensor del Pueblo de la Policía del Estado de São Paulo (2018), disponible en ftp://ftp.sp.gov.br/ ftpouvidoria-policia/Anual2018.pdf (última consultación en enero 2022).

8 Una línea de estudios etnográficos sobre el mundo del crimen en Brasil se ha construido en oposición a la noción normativa y legal del crimen organizado (Hirata 2018; Telles 2010; Biondi 2018; Feltran 2016). 
en trayectorias o viajes como conectores fundamentales para la comprensión de una sociedad social globalizada. Más allá de la idea de flujos, ensamblajes y líneas de fuerza reveladas, estos autores proponen una teoría incrustada en situaciones empíricas concretas. Tal teoría sería forzosamente muy plural. En ese texto reconstruimos la jornada del Ford Ka sobre todo a partir de etnografías realizadas entre 2015 y 2020 en favelas, subastas, aseguradoras y deshuesaderos de São Paulo. En esa investigación teníamos dos preguntas empíricas: ¿cómo funciona y cuánto vale? Exponemos acá parte pequeña de esa investigación más amplia. En el debate sobre movilidad (Urry 2002, 2004, 2010; Freire-Medeiros, Telles y Allis 2018; Martins Jr. 2015), la reciente contribución de Amit y Knowles (2017) propone la noción de tacking para comprender los espacios de la improvisación diária de los actores, ya sean dominantes o subordinados, en la construcción de sus propias posibilidades de acción. Esta improvisación incluye la invención, el tiempo y lo inesperado, e intenta describir la forma recurrente, aunque poco discutida, en la que los sujetos contemporáneos navegan en su vida cotidiana. ${ }^{9}$ Las oportunidades para la supervivencia y los negocios, la generación de ingresos, la movilidad y la producción de formas de vida también serían, en gran medida, resultado de la improvisación situacional frente a barreras muy diferentes y problemas cotidianos, porque el mundo ha estado cambiando rápidamente.

\section{EL ROBO}

Todavía en la zona este, pero ahora en la frontera con la región ABC Paulista, un conductor de uber, Diego, conducía un Ford Ka Sedan 2018 alquilado. Diego acababa de estacionar el automóvil frente a su casa y permaneció en el vehículo por un minuto, intercambiando mensajes con su próximo cliente, a quien se suponía que debía recoger frente a un Banco do Brasil, en la Avenida Sapopemba, en 20 minutos. Blanco, con los ojos verdes y el cabello revuelto de gel, Diego, de 36 años, había residido en la periferia de São Paulo desde que nació. Sabía que la ubicación no era un lugar muy seguro, pero tenía que aceptar las solicitudes en la aplicación para mantener una buena puntuación y ganar bonos. Diego incluso había tenido su propia historia en el mundo del crimen local, traficando y usando drogas desde la adolescencia hasta la edad adulta. Además, Diego negociaba motocicletas. Compró y vendió muchas usadas, de cualquier fuente, incluidos robos y hurtos. Una vez fue arrestado por posesión ilegal de un arma de fuego, pero dice que rara vez salió armado. "Nunca supe cómo robar, no lo sé [hace una mueca pensativa, moralmente desaprueba tales

9 El planteamiento propuesto por los autores, aunque no referenciado, puede relacionarse directamente con el de las teorías de Simmel (2010), así como con los resultados de esta producción, tanto en el clásico Goffman (2016) y posteriormente en Cefaï y Gardella (2011). 
actos violentos], de hecho, no me gusta; pero siempre he estado en la calle, siempre con niños de por aquí", nos cuenta en una entrevista.

Como ironía del destino, Diego ahora se convirtió en víctima de los niños que en 2018, como lo había hecho 15 años antes, ocuparon los puestos de primera línea en el mercado de vehículos robados. Durante esos 15 años desde que cumplió esa "función", como él dice, Diego narra algunos puntos de inflexión clave. Además de la prisión, cita su matrimonio en 2010, que analiza en relación con una conversión religiosa al pentecostalismo y describe como "una bendición", y sobre todo el nacimiento de su hija en 2015. Su conversión matrimonial y su hija, lo que lo transformó en un "hombre de familia", ayudó a Diego, en sus términos, a "tener otra cabeza". Todos los días en las redes sociales publica fotos con su familia y, los domingos, se pone en traje a camino a la iglesia. Diego habla mucho de la importancia de la familia. Antes de que lo robaran, Diego ya se había convertido en un ferviente defensor de la candidatura de Jair Bolsonaro para la presidencia de Brasil, y continuó apoyando al presidente en el cargo, hasta mediados de 2020. Nos dice con orgullo que había abandonado toda actividad ilegal. Él ha estado vendiendo y comprando autos usados por cuatro años. Sin embargo, cuando le preguntamos si podemos seguir su rutina más de cerca, en nuestra etnografía, y especialmente cuando le pedimos más detalles sobre cómo funciona su negocio hoy, Diego duda.

Cortésmente se niega a ayudarnos con nuestra investigación a este nivel de detalle. Más tarde confía a uno de nosotros investigadores que si "comienzas a mirar muy de cerca" no hay nadie involucrado con los autos a quien no tocará nada ilegal. "Es imposible no hacerlo, isabes?, porque todos lo hacen". Diego se presenta, en su vida familiar, en su religión y entre sus amigos, como un hombre con una vida limpia y una conducta intachable. Económicamente todavía depende de los mercados ilegales de automóviles de São Paulo y, para complementar esto, hay sus ingresos como conductor de uber. A veces compra autos manipulados, de origen ilegal, para revenderlos. A veces engaña al odómetro, usa partes de origen ilegal en los autos que revende; estos son todos los procedimientos que forman parte del negocio, nos dice. Pero él no roba autos, eso es diferente. Él gana 3-4 SM por mes, en promedio, conduciendo con uber. En el mercado formal, solo un automóvil comprado a un precio muy bajo, debido a que tiene orígenes ilegales, puede darle el doble y con "documentos calientes", que no despiertan ninguna sospecha.

A las 8:40 de la noche del 2 de octubre de 2018, Diego fue robado frente a su propia casa. Cuando salió del Ford Ka, tenía dos bolsas en la mano y trató de cerrar el vehículo manualmente. Como había estacionado en el lado derecho de la calle, los autos que pasaban por él tuvieron que girar ligeramente alrededor de su cuerpo. Era una situación vulnerable. Tan pronto como logró cerrar la puerta y giró para cruzar la calle, cuatro chicos se acercaron a Diego. Dos cubrieron la parte trasera y dos se le acercaron de frente, uno apuntando 
con un revólver de calibre 38. El ladrón armado llevaba chanclas, pantalones cortos y una sudadera con capucha, aunque la capucha estaba baja. El otro chico que se acercó a Diego tenía la capucha puesta y vestía zapatillas y jeans.

Su ropa mostraba que uno de los muchachos se había preparado claramente para el robo y la eventual fuga, mientras que al otro ni siquiera le importaban esos detalles. Dentro de esta escena, nos gustaría hablar sobre Michael, uno de los dos niños que se quedaron atrás, brindando cobertura a sus colegas. Con la piel morena, más clara que los dos asaltantes, Michael no se consideraba negro. "Moreno" era la forma en que un colega se refería a él. ${ }^{10}$

Michael es un chico alto, extremadamente tímido. No nos miró a los ojos cuando hablamos con él en la casa de los padres de Big G, donde había vivido durante esas semanas. Big G había ordenado el robo del Ford Ka a unos amigos de Michael, para utilizarlo en un otro robo que haría con otros colegas del crimen en los próximos días. Él nos decía en entrevista que Michael había llegado a la gran ciudad dos semanas antes, después de dos semanas viviendo en las calles de Guarujá, en la costa de São Paulo. Los padres de Big G lo conocieron allí y, al ver que no tenía el perfil típico de una persona sin hogar, le ofrecieron ayuda. Sin ningún lugar a donde ir, Michael aceptó la oferta. Los padres de Big G lo llevaron a casa con ellos, y él se convirtió en un miembro de la familia durante esas semanas.

La madre de Big G encontró un abanico y un colchón para él, y también lo alimentó. "Si hay suficiente para dos, hay suficiente para tres", nos dijo. A cambio, Michael tuvo que volver a la escuela. Este tipo de solidaridad popular sigue siendo común hoy en día en las periferias urbanas. Los padres de Big $\mathrm{G}$ se sintieron bien ayudando a una persona joven que estaba pasando por un momento muy difícil. Michael no sabe quiénes son sus padres, ni conoce a nadie en su familia. De niño, en la casa de huéspedes donde creció, escuchó que su madre vivía en Guarujá.

Trabajó en la pensión a cambio de comida y alojamiento hasta los 18 años. Sin dinero, pero con algo de educación secundaria, lo sacaron a la calle. Solo necesitaba dos años más, o uno, si también tomaba clases nocturnas, para "terminar sus estudios", como dicen aquellos que ni siquiera soñarían con ir a la universidad. En busca de su madre, o su imagen idealizada de ella, Michael hizo autostop a Guarujá. Encontró a una mujer que creía que era ella, pero no tuvieron la reunión que esperaba. Michael se quedó en la calle durante unos días e intentó beber para mantenerse caliente, pero no tenía experiencia.

10 Los diagramas de identificación racial en Brasil, y especialmente en São Paulo, han sufrido cambios significativos. El diagrama dominante, basado en el racismo hegemónico durante el siglo XX y capturado por la noción de "democracia racial", ha sido cuestionado en las últimas décadas por uno más cerca de la de América del Norte: one drop rule. 
Comenzó a salir con algunos niños de la calle y acompañarlos en sus actividades, incluido el robo de supermercados.

En São Paulo, en la casa de la madre de Big G, comenzó a pasar el rato en la esquina con algunos niños de la misma edad. Uno de esos días, cuando todavía era un recién llegado al grupo, acompañó a los niños en una escena de robo, sin estar muy seguro de lo que sucedería. Michael estaba en la escena del robo del Ford Ka de Diego, un robo violento, sin saber qué pasaría. El mundo del crimen es un espacio inclusivo, en el que muchas personas desempleadas como Michael, que están excluidas de otras redes, pueden ingresar. El mundo del crimen también es un lugar peligroso, donde muchas personas desempleadas como Michael, a través de la vacilación o la adrenalina, pueden perder la vida.

Diego no ofreció resistencia cuando fue confrontado. El niño armado tomó las llaves y subió al auto del lado del conductor, mientras que el otro, a su lado, le robó la billetera y una bolsa que contenía las pertenencias de Diego. Solo después de hacerlo, el niño rodeó el auto y se subió al asiento trasero. La precariedad del "trabajo" en el circuito de robo a mano armada es tan grande que a veces estos pequeños objetos robados del vehículo ganarán a los jóvenes ladrones más dinero que el propio vehículo. Algo aturdido, Michael y su compañero también se subieron al auto robado. Los cuatro muchachos se apresuraron. La acción duró menos de un minuto, y la adrenalina que sintieron pareció compensar el miedo.

Diego estaba parado en medio de la calle, todavía en estado de shock. Al igual que muchos otros conductores de uber, Diego alquiló un automóvil para trabajar e inmediatamente pensó para sí mismo que el automóvil estaba asegurado, por la propia empresa de alquiler, y por lo tanto su pérdida no sería demasiado grande. Las compañías de alquiler de automóviles ofrecen planes de seguro especiales para los conductores de uber en São Paulo. Sin embargo, robos como este no fueron infrecuentes en la ciudad en 2018. Era muy común escuchar a los conductores comentar sobre los riesgos que enfrentaban en el trabajo. Diego no tuvo que pagar el alquiler del auto. Había seguro.

\section{UNA FAVELA, 9:30 PM}

Acabábamos de terminar otro día de trabajo. Nos dirigíamos a lo largo del callejón central de la favela, el único por donde los autos pueden pasar, hacia un bar propiedad de un amigo, que había sido un interlocutor en nuestra investigación durante muchos años. Estamos flanqueados por chozas de madera, ladrillo bahiano y ventanas de metal, a ambos lados del callejón. También hay mucha basura y escombros que los perros sueltos buscan para comer. A veces, incluso los residentes más pobres, como Sebastiana, que nos acompañó ese día, hurgan en la basura en busca de comida. 
Mientras caminábamos, un Ford Ka Sedan blanco rodó por el callejón en silencio, pero visiblemente. El auto tocaba música funk prohibido, ${ }^{11}$ y la ventana delantera estaba rota. Cuatro jóvenes, todos sonriendo, estaban sentados adentro mientras se detenía en el bar "Sacode a poeira", donde también nos dirigíamos. Michael está en el asiento trasero y abre la ventana cuando el vehículo se detiene cerca de nosotros, y vemos el humo saliendo del vehículo. Luego viene el fuerte olor a marihuana. Michael se ríe, hablando con uno de sus compañeros. Cuando nos ven, los muchachos llaman a Sebastiana, la conocen del barrio. Ella va a la ventanilla del auto, habla con ellos y regresa. Querían saber quiénes éramos. A primera vista, ya podían decir que no éramos de allí, como sería el caso en cualquier favela en São Paulo. Sebastiana dice que somos amigos, que hemos estado investigando en el vecindario por algún tiempo.

Los muchachos están tranquilos. El trabajo acababa de completarse: el Ford Ka alquilado que Diego usó en su trabajo como conductor de uber había sido robado recientemente. Ahora estaba estacionado frente a un bar, en una de las 40 favelas en Sapopemba. Esta se considera una pequeña favela, con una población de 7300 en 2019. La favela fue construida en un valle entre dos colinas en la década de 1960 y desde entonces ha crecido dentro de los límites impuestos por las calles circundantes y gradualmente se ha consolidado a medida que los residentes mejoraron su autoestima. Cabañas construidas. Las casas de madera improvisadas dieron paso a bloques de ladrillo, las baldosas de asbesto fueron reemplazadas gradualmente por baldosas de hormigón corrugado y, por lo tanto, la favela se urbanizó (Cavalcanti 2007; M. Silva 2017). La vieja corriente contaminada en el fondo fue canalizada por el gobierno de la ciudad y se convirtió en lo que hoy es el callejón central. En cada colina, hay empinadas escaleras de hormigón, de aproximadamente un metro de ancho, que llevan a los residentes a sus hogares. No hay recolección de basura en la parte inferior de la favela, por lo que la basura se acumula en las laderas, arrastrada por la lluvia que también derriba cuatro o cinco chozas al año ubicadas en áreas en riesgo. Entre 2014 y 2020, una época de crisis económica en el país, se construyeron muchas chozas nuevas, algunas ubicadas debajo de esta acumulación de basura y otras chozas en riesgo.

"Al llegar al bar, vemos niños conversando en los tejados, donde los niños un poco antes habían estado volando cometas. Ahora los mismos niños corrían por las calles jugando, vigilados por mujeres negras. Después de cinco

I I El funk es un ritmo musical que se originó en las periferias, especialmente en Río de Janeiro y posteriormente en São Paulo. El ritmo está marcado por unos bajos que remiten a los tambores, sonidos de disparos y motos. El llamado estilo prohibido con frecuencia tiene como tema el mundo del crimen. Ver Mattos (2017). 
minutos, el niño que conducía el Ford Ka reaparece, con pantalones cortos de poliéster hasta las rodillas y chanclas. Está sin camisa, delgado pero musculoso, y ahora está limpiando el piso con una escoba y un balde de agua. En la misma mano que sostiene la escoba, hay un cigarrillo encendido, y de vez en cuando toma una bocanada. Tiene algunos tatuajes caseros pequeños en el antebrazo y el pecho. El mismo tipo que robó el auto, trabaja en el bar. Se había quitado el gorro rojo que llevaba antes. Después de robar el auto con sus amigos, escuchar funk y fumar un porro, había entrado a trabajar. Siempre había música sonando allí. Escuchar música no es una elección individual: la favela reproduce música para todos, a gran volumen y casi todo el tiempo." (Maldonado, cuaderno de campo, 2019)

\section{DESHUESADERO}

Maurício estaba parado detrás del mostrador grande en su Stratus Desmonte cuando llegó la grúa con un Ford Ka Sedan 2018 blanco estrellado, el mismo auto que le habían robado a Diego, utilizado en un robo a un cajero ATM, destrozado mientras Big G intentaba huir de la policía. Maurício es un hombre alto y blanco con ojos verdes, una larga barba marrón y el pelo bien cuidado. Es hijo de una madre brasileña y de un padre portugués que llegó a Brasil en la década de 1960. Con 33 años (en 2020), Maurício es el más joven de los tres hijos de la pareja. Nacido y criado en São Paulo, Maurício siempre ha vivido en los barrios de clase media de la parte sur-central de la ciudad.

Ingeniero de formación, Maurício es obstinado y serio, mejoró mucho de vida desde sus orígenes humildes. Fue uno de nuestros principales entrevistados en el mundo de los deshuesaderos que buscamos comprender como segmentado, estratificado y diverso (Pinho, Zambon y Silva 2021). En un polo están las grandes operaciones de desmantelamiento industrial propiedad de grupos de seguros e infundidas con una retórica de responsabilidad social y ambiental corporativa. En el otro polo está la gran variedad de almacenes clandestinos y tiendas ilegales. Más lejos aún están las operaciones de calles abiertas donde los automóviles se desmantelan a plena luz del día en los bordes traseros de las favelas. Stratus Desmonte se encuentra en algún punto entre estos polos.

Maurício abastece al mercado de autopartes originales y usadas que provienen de automóviles destrozados o robados. Es un mercado valorado en dos mil millones de dólares al año en Brasil. El mercado de piezas de vehículos emplea prácticas integradas, gracias a las plataformas de ventas en línea, entre otros factores. Un vehículo desmantelado en una tienda de despiece en las afueras de la ciudad, cuyas partes se venden en línea individualmente, crea competencia tanto para los grandes fabricantes de automóviles que venden piezas originales como para los grandes desmanteladores industriales. En 2019, según 
la Unión Brasileña de Propietarios de Chatarra (SBD), el 80\% de las ventas de autopartes se realizaron en el sitio web Mercado Livre. Las piezas de automóviles robados a menudo se venden en esta plataforma.

Maurício nos dijo que el Ford Ka 2018 que llegó a Stratus Desmonte, un miércoles de enero de 2019, había venido del patio de Auction Corp en Guarulhos y había sido comprado por compradores profesionales. Ocupado como siempre, nos dice que estos profesionales especializados valen su precio. Se pueden encontrar buenas ofertas en subastas con un ojo experimentado. Maurício nos dice que era necesario modernizar su propia operación, incluso si al principio no quería hacerlo. El comprador gana menos de $1 \%$ del precio, el dueño de la subasta 5\% por sobre el precio de venta (el Ford Ka costa 60 SM, se vende en subastas por cerca de $20 \%$ menos).

\section{Figura 1}

Comparación entre ganancias, características sociales, condiciones de vivienda y exposición a la violencia entre los operadores de subastas en São Paulo.

\begin{tabular}{|c|c|c|c|c|c|}
\hline & $\begin{array}{l}\text { Propietario } \\
\text { de seguradora } \\
\text { (persona } \\
\text { jurídica) }\end{array}$ & $\begin{array}{l}\text { Propietario } \\
\text { de subasta } \\
\text { (persona } \\
\text { física) }\end{array}$ & Comprador & $\begin{array}{l}\text { Ladrón } 1 \\
\text { Big G }\end{array}$ & $\begin{array}{l}\text { Ladrón } 2 \\
\text { Michael }\end{array}$ \\
\hline $\begin{array}{l}\text { Ganancias directas } \\
\text { del Ford } \mathrm{Ka}\end{array}$ & $\begin{array}{l}48 \\
\mathrm{SM}\end{array}$ & $\begin{array}{l}2,4 \\
\text { SM }\end{array}$ & - & - & - \\
\hline $\begin{array}{l}\text { Ganancias de subasta } \\
\text { de día completo }\end{array}$ & $\begin{array}{l}928,7 \\
\text { SM }\end{array}$ & $\begin{array}{l}46 \\
\mathrm{SM}\end{array}$ & $\begin{array}{l}0,5 \\
\mathrm{SM}\end{array}$ & - & - \\
\hline $\begin{array}{l}\text { Características } \\
\text { sociales }\end{array}$ & $\begin{array}{l}\text { Elite económica } \\
\text { blanco, } \\
\text { global }\end{array}$ & $\begin{array}{l}\text { Elite económica } \\
\text { blanco, } \\
\text { nacional }\end{array}$ & $\begin{array}{l}\text { Clase obrera } \\
\text { negro, ciudad } \\
\text { provincial }\end{array}$ & $\begin{array}{l}\text { Urbano } \\
\text { marginado } \\
\text { Negro }\end{array}$ & $\begin{array}{l}\text { Urbano margi- } \\
\text { nado operador } \\
\text { local negro de } \\
\text { bajo nivel }\end{array}$ \\
\hline $\begin{array}{l}\text { Ciudad } \\
\text { de residencia }\end{array}$ & São Paulo & $\begin{array}{l}\text { Región } \\
\text { metropolitana } \\
\text { de São Paulo }\end{array}$ & $\begin{array}{l}\text { Región } \\
\text { metropolitana } \\
\text { de São Paulo }\end{array}$ & $\begin{array}{l}\text { Área } \\
\text { metropolitana } \\
\text { de São Paulo }\end{array}$ & $\begin{array}{l}\text { Área } \\
\text { metropolitana } \\
\text { de São Paulo }\end{array}$ \\
\hline $\begin{array}{l}\text { Condiciones } \\
\text { de vivienda }\end{array}$ & $\begin{array}{l}\text { Apartamentos } \\
\text { o casas de lujo } \\
\text { condominios } \\
\text { cerrados }\end{array}$ & $\begin{array}{l}\text { Casa de lujo } \\
\text { en un } \\
\text { condominio } \\
\text { cerrado }\end{array}$ & $\begin{array}{l}\text { Casa } \\
\text { autoconstruida } \\
\text { en barrio } \\
\text { periférico }\end{array}$ & $\begin{array}{l}\text { Casa } \\
\text { autoconstruida } \\
\text { en barrio } \\
\text { periférico }\end{array}$ & $\begin{array}{l}\text { Comparte casa } \\
\text { autoconstruida } \\
\text { en barrio } \\
\text { periférico }\end{array}$ \\
\hline $\begin{array}{l}\text { Riesgo de criminali- } \\
\text { zación y exposición } \\
\text { a la violencia }\end{array}$ & Ningún & Ningún & Bajo & Alto & Muy alto \\
\hline
\end{tabular}

Fuente: elaboración propia. Los autores agradecen especialmente a André de Pieri Pimentel y Luiz Gustavo Pereira. 
Maurício espera hacer 100 SM con el auto desmantelado, pero eso va a tardar años hasta que venda todas las partes. Stratus es uno de los muchos desmanteladores alineados en la Avenida Vitrine, en el sur de São Paulo. Es una operación notable por su gran tamaño y organización. Vitrine es una importante avenida con mucho tráfico en ambas direcciones, que conecta el barrio de Ipiranga, el más antiguo de la ciudad de São Paulo, con el llamado ABC Paulista y la costa. ${ }^{12}$ Una línea de metro cruza la avenida además de muchas líneas de autobuses de alta intensidad. El área cuenta con excelente infraestructura de transporte público. A lo largo de la avenida se encuentran los barrios residenciales de clase media y los nuevos edificios de apartamentos de clase media alta que datan del auge del mercado inmobiliario más reciente de fines de la década de 2000. Ahora se encuentran donde antes estaban las viviendas de bajos ingresos. El Stratus ocupa una buena parte del bloque en un área de aproximadamente 3300 metros cuadrados. Los tres pisos con cadáveres de automóviles apilados en estantes altos se pueden ver desde lejos. En la entrada de la tienda hay un mostrador grande para servicio al cliente y dos más pequeños que separan los sectores minoristas de motores y luces.

Como siempre, Maurício llevaba un casco y una camisa roja con el nombre de su compañía bordado en el pecho. Habló por teléfono con un cliente, jugueteó con la computadora y habló con uno de sus empleados. En 2019, había 15 personas trabajando en Stratus. El día ya estaba ocupado; otro coche había llegado para ser desmantelado. En promedio, cuatro o cinco llegan cada semana. Maurício nos vio, saludó desde lejos y nos indicó que esperáramos. Siempre curiosos investigadores, nos quedamos en la acera en frente y miramos a nuestro alrededor. Mientras descargaban el Ford Ka, un auto de la policía estacionó en la calle frente a Stratus. Dos policías salieron del auto y se dirigieron al mostrador. Uno de ellos le preguntó a Maurício sobre una parte en particular y rápidamente respondió que no había ninguna disponible. Luego los envió a otra tienda para probar suerte. El tono de la conversación fue amigable; los policías le agradecieron y regresaron al vehículo. A pesar de que la interacción fue excepcional, la presencia de agentes de policía en las tiendas de chuletas siempre es motivo de preocupación. Al observar a Maurício y sus empleados durante la interacción, nos quedó claro que todos estaban en alerta.

Es común que los policías uniformados realicen pequeñas tareas en medio de su turno de trabajo, como pausas para tomar café en las panaderías locales, viajes al banco o algunas compras. Mientras realizan estos recados, desarrollan sus redes de contactos que en otros contextos podrían confundirse con

12 La región $\mathrm{ABC}$ es la principal zona industrial en el gran São Paulo y en Brasil. El acrónimo se refiere a las tres ciudades que originalmente formaron la región: Santo André (A), São Bernardo do Campo (B) y São Caetano do Sul (C). La región es conocida por su historia proletaria y por la enorme desigualdad del mundo industrial latinoamericano. Mientras que São Caetano cuenta con el IDH más alto de Brasil, las favelas de Santo André y Sapopemba tienen focos de extrema pobreza. 
las redes de extorsión (Whyte 2005). Saber cómo jugar diferentes juegos, en diferentes tableros, es el arma principal para una vigilancia efectiva (Das 2007; Almeida 2019). En este caso, podrían haber estado buscando piezas para sus autos, pero también podrían haber estado tomando nota de cualquier cosa inusual en la tienda.

Apasionado por los automóviles y las motocicletas, Maurício siempre ha soñado con trabajar en el mercado automotriz, pero nunca con ser dueño de la tienda de la familia. "Es un mercado estigmatizado", comentó su padre, seu Joaquim. Los desmanteladores son donde vienen las piezas robadas. El propio Maurício sabe que los robos continúan suministrando tiendas de diferentes tipos, e incluso mientras acepta autos robados, como nuestro Ford Ka, quiere diferenciarse de la competencia. Los requisitos técnicos, burocráticos y legales para la operación de una planta de desmantelamiento totalmente legalizada son varias veces más onerosos de lo que conllevan menos operaciones legales. También son muy diferentes la organización de los espacios físicos y la magnitud de su funcionamiento. Esta heterogeneidad en la práctica, pero con una representación homogénea de ilegalidad en todo el sector desde 2014, ha producido diferentes clasificaciones y procesos de criminalización de los desmanteladores.

\section{PRECIOS Y ESTRATIFICACIÓN}

Maurício necesita ser más eficiente económicamente que los deshuesaderos de las aseguradoras, los más ricos, pero necesita ser más legal que los "desmanches" más clandestinos. Stratus debe parecerse al primero y competir en precios con el segundo. Pero es muy difícil competir con estos dos modelos comerciales opuestos. "Recicla", nombre de un establecimiento del primer modelo, cuenta con el respaldo de una gran compañía de seguros y la protección de la policía. Las grandes tiendas criminales, el PCC y la protección de sus armas han vuelto a las tiendas y almacenes. Maurício compite por el espacio intermedio.

Maurício no ofrece una lista de precios estándar en Stratus. El precio y la parte vendida se deciden en el momento y quedan a criterio del vendedor. Al monitorear la operación en Stratus, observamos los precios de venta de las piezas Ford Ka 2018 en comparación con los precios de venta en otras tiendas de despiece (figura 2).

Si bien Maurício no puede competir en precios con las pequeñas tiendas ilegales que se encuentran en toda la ciudad y desmantelar la mayoría de los automóviles en São Paulo, su estrategia de ventas es diferenciarse de las tiendas que venden "partes con sangre". Sin embargo, puede vender piezas a precios más bajos que los desmanteladores grandes y ejemplares como Recicla. Un desmantelador como Stratus opera en un mercado determinado por dinámicas sociales y económicas únicas. Los precios se determinan no solo por la 
Figura 2

Comparación entre precios de partes idénticas por tipo de operación de desmantelamiento

\begin{tabular}{lcccc} 
& $\begin{array}{c}\text { Compresor de aire } \\
\text { [Ford Ka 2018 } \\
- \text { USD] }\end{array}$ & $\begin{array}{c}\text { Compresor de aire } \\
\text { [Ford Ka 2018 } \\
- \text { SM] }\end{array}$ & $\begin{array}{c}\text { Diferencia } \\
\text { de precio } \\
\text { [porcentaje] }\end{array}$ & $\begin{array}{c}\text { Diferencia } \\
\text { de precio } \\
\text { [veces] }\end{array}$ \\
\hline $\begin{array}{l}\text { Concesionario Ford autorizado } \\
\text { [parte nueva] }\end{array}$ & 733,75 & 2,94 & $100 \%$ & $16 \times$ \\
\hline $\begin{array}{l}\text { Recicla Desmonte Sustentável } \\
\text { [parte usada] }\end{array}$ & 225,00 & 0,90 & $29 \%$ & $10 \times$ \\
\hline $\begin{array}{l}\text { Stratus Desmonte } \\
\text { [tienda fisica parte usada] }\end{array}$ & 137,50 & 0,55 & $19 \%$ & $9 \times$ \\
\hline $\begin{array}{l}\text { Stratus Desmonte } \\
\text { [en línea, parte usada] }\end{array}$ & 125,00 & 0,50 & $17 \%$ & $1 \times$ \\
\hline $\begin{array}{l}\text { Almacenes ilegales [en línea, parte } \\
\text { usada, precio más bajo encontrado] }\end{array}$ & 13,80 & 0,045 & $1,8 \%$ \\
\hline
\end{tabular}

Fuente: los autores, basados en datos etnográficos obtenidos de desmanteladores, aumentados por búsqueda en línea (2018-2020).

intervención estatal sino también por la competencia con mercados ilegales que están regulados por facciones criminales y están a merced de la discreción de la policía. Los comportamientos normativos estatales/legales, penales y policiales coexisten en el mercado de desmantelamiento.

Es importante tener en cuenta que el comportamiento de los oficiales de policía a nivel de calle no debe confundirse con las políticas oficiales establecidas por la propia institución policial. Los agentes de policía a nivel de calle trabajan en el punto de interfaz entre las normas legales y los códigos de conducta criminales y deben saber cómo y cuándo actuar bajo un conjunto de reglas u otro. El papel primordial de la policía en la clasificación de los establecimientos de desmantelamiento mediante la aplicación selectiva, y el impacto de esa clasificación en los negocios diarios, subraya la interfaz entre un régimen legal apropiado y uno penal apropiado. Grupos policiales que venden protección a chuleterías, como las milícias en Río de Janeiro, extorsionan a los propietarios legales e ilegales. La génesis de su protección es su control de armas de fuego. ${ }^{13}$ 
Esta triangulación normativa entre el Estado, el mundo del crimen y los agentes del mercado define la vida cotidiana y sus discursos en las periferias de la ciudad (Beraldo 2020; Feltran 2020; Maldonado 2020). Cada régimen define su propio código moral: diferentes ideas de justicia y comportamiento aceptable. Maurício se siente completamente alejado del robo del Ford Ka incluso cuando lo desmonta. Recicla podría estar haciendo lo mismo. Los regímenes no solo operan en los ámbitos morales y administrativos que crean códigos de conducta y un sentido de justicia. También operan en mercados monetizados. Si Maurício no paga a la policía, su negocio podría ser inspeccionado por el Estado, su sustento podría estar en peligro y él mismo podría enfrentar sanciones legales. El dinero en estos casos claramente juega un papel fundamental en la mediación del conflicto urbano (Feltran 2014).

Durante nuestras primeras visitas de campo, nuestros entrevistados clasificaron a los desmanteladores en dos tipos: legales e ilegales. Nuestra investigación revela un tapiz situacional más complejo. El Ford Ka robado de Diego ayudó a Stratus Desmanche a distanciarse del "mundo del crimen". Maurício comprende esta multiplicidad de normatividades, intereses y actores reguladores en lucha. Él entiende cómo la política define estas situaciones, pero también que la política a menudo se practica fuera de los canales oficiales. Sabe también que deshuesaderos legales o clandestinos todavía comparten el mismo mercado. También comparten la misma ciudad, país y mundo, todos los cuales están conectados por estos mercados. La alienación de los roles que desempeñamos en este sistema parece ser un requisito previo para definir la violencia como perteneciente al otro, especialmente aquellos que parecen criminales.

En una avenida lejana de la zona este de São Paulo, en febrero de 2019, la víspera del Carnaval, le preguntamos a un joven empleado negro cuándo la tienda de autopartes podría entregarnos un motor de Ford Ka con números de serie de chasis retocados. Ni el empleado joven y negro ni otros dos empleados negros pudieron responder: inmediatamente miraron a un hombre blanco, de unos 50 años, el dueño de la tienda. Él respondió por ellos: los jóvenes no querían "trabajar" durante el Carnaval. "Vuelve después del Carnaval cuando las cosas vuelvan a la normalidad". El motor estaría listo la semana siguiente. El hombre usó el verbo informalmente, "trabajar", a menudo usado en el mundo criminal de São Paulo como un sustituto contextual de robar.

\section{NOTAS FINALES}

Para el sentido común los mercados ilegales, el crimen y la violencia existen en oposición directa a los mercados legales que funcionan en un orden civilizado. Por esta razón, informes de las principales asociaciones empresariales brasileñas hacen estimaciones del tamaño de los mercados ilegales en el país (FIESP 2017). Si bien los defectos metodológicos en el estudio son tan notorios que 
no vale la pena citar sus cifras aquí, es importante tener en cuenta la justificación que subyace a sus conclusiones: estos informes corporativos afirman que los miles de millones de dólares que se manejan anualmente en las economías brasileñas ilícitas se restaron de los nacionales PIB, año tras año. Los mercados ilegales roban riqueza de los mercados legales. El PIB brasileño es víctima de la depredación por parte de los mercados ilegales (Rabossi 2018).

Como si el dinamismo del sector brasileño de autopartes no viniera de los cobertizos ilegales que desmantelan los automóviles robados. Como si por cada reclamo de seguro pagado en el caso de robo de vehículos nuevos, la industria automotriz no vendería otro automóvil nuevo. Como si el mercado de las artes formales no se calienta con los recursos que un dueño de subasta extrae de los vehículos robados como nuestro Ford Ka. Como si ese mismo dinero no generara impuestos para el Estado brasileño y los gobiernos extranjeros, y no afectara el desarrollo económico de más de un país.

Las historias de cada uno de estos autos, compañías y personajes demuestran que la idea de polaridad entre legal e ilegal, mediada por la ley estatal, pudo haber sido un proyecto útil para la sociedad urbana latinoamericana, pero no es más que un marco inexacto y normativo para describir el conflicto urbano contemporáneo. Una imagen más precisa es la de una frontera porosa entre lo legal y lo ilegal cerca de la cual abundan empresas, negocios muy rentables. Una imagen de cómo estas compañías manipulan la ley y el uso de la fuerza. Después de concluir esta investigación, la idea de polos opuestos legales e ilegales nos parece más una cortina de humo ideológica que un reflejo de la realidad contemporánea. Obstruir la consideración de la interacción del mundo real entre lo legal y lo ilegal condena la vida cotidiana urbana a un emparejamiento categórico inexacto vinculado a la reproducción de desigualdades persistentes, tales como: atraso/progreso; subdesarrollado/desarrollado; pobre/rico; blanco/negro; hombre/mujer (Tilly 1998).

Concebida de la manera que envasa la investigación, de otro lado, la polaridad legal-ilegal no es simplemente deconstruida, como si no produjera efectos desiguales concretos que realmente existen en el mundo social. Hay muchos Michaels realmente asesinados en Brasil; los valores que los actores centrales y marginales extraen de los automóviles robados son realmente muy desiguales y crean saldos bancarios muy desiguales y reales para las personas a lo largo de sus jornadas de vida. Como Pierre Bourdieu (2013) señaló en un ensayo hacia el final de su carrera, la objetivación de lugares desiguales en el espacio social también es objetiva en el espacio físico y en las estructuras mentales. En los barrios ricos con su arquitectura moderna brutalista, hormigón armado, pisos de madera y vidrio templado; en barrios pobres con su ladrillo bahiano, pisos de madera en bruto y baldosas de cemento corrugado.

Escapando de esta polaridad desde un punto de vista analítico, nuestra perspectiva relacional sugiere que la frontera entre lo legal y lo ilegal debe 
entenderse como un espacio de la regulación política de la acumulación de capital, defendida con violencia siempre que sea necesario. También es a lo largo de esta frontera que vemos el funcionamiento de los mecanismos de producción y reproducción de las desigualdades urbanas. Si es una frontera, las intervenciones y los significados característicos de esta regulación son la dimensión analítica fundamental. Es una regulación que se realiza diariamente y en dimensiones contrastantes: burocracia estatal, moral-religiosa, economía y conflictos violentos. Es una regulación llevada a cabo con diferentes intensidades y ritmos y por diferentes agentes estatales que actúan legalmente, agentes estatales que negocian mercados de protección, así como los agentes criminales, religiosos y los empresarios liberales y morales de cada sociedad.

Son los actores más subalternos de esos mercados los que siempre llevan a cabo la violencia criminal, por aceptaren tomar su riesgo para intentar ganar un poco más que ganarían en las economías formales. En São Paulo, son por ejemplo esos ladrones de vehículos actuando en el ritmo del PCC u oficiales de policía que actúan por su propia cuenta fuera del marco legal. Cuanto más central es el actor en estos mercados, "menos se ensucia las manos con sangre", como dice el dicho en Brasil. Se supone que alguien más se ensuciará las manos por él. Cuanto más marginal es, más riesgo corre y menos beneficios recibe. En cualquier caso, el potencial de ganancia económica en los mercados ilegales en comparación con los mercados legales es la razón principal por la cual los jóvenes en los barrios bajos se involucran en empresas ilegales. Un cambio en este diferencial ciertamente haría que ciudades como São Paulo fueran mucho menos violentas.

En São Paulo, la competencia por los recursos que circulan en los mercados de vehículos, tanto legales como ilegales, genera riqueza para muchas personas. Los consumidores de cocaína en Londres, los asegurados en Brasil y los compradores de vehículos y autopartes inyectan dinero en una economía cuyas ganancias se dividirán de manera muy desigual entre todos los involucrados en su operación, desde los más centrales a los más marginales. La violencia estatal legal dirigida a los ladrones está empíricamente vinculada a los intereses - sobre todo económicos - de los grupos dominantes locales, centrales o subordinados. La policía actúa para proteger las ganancias de los dueños de aseguradoras y subastas, y por aquellos que aceptan su propio dominio, como las clases medias. Las formas en que operan los mercados de automóviles robados hacen dinero y hacen la ciudad. Las formas de gobierno público / privado / criminal que los regulan, ${ }^{14}$ siempre en el límite entre legalidad e ilegalidad, ${ }^{15}$

14 La sociología de la acción pública y la idea de gobernanza según lo expuesto por Lascoumes y Le Galès (2012) nos ayudan a pensar cómo se regulan estos mercados en situaciones cotidianas.

15 Guyer (2004), Telles (2010), Rabossi (201 1, 2015), Hirata (2018), Feltran (2014), Dewey (2015, 2016), Beckert y Dewey (2017). 
reproducen desigualdades urbanas duraderas (Tilly 1998). Veíamos cuánto dinero circula durante cada una de las etapas después de un robo, y las formas en que este dinero, así como otros recursos relacionales, se distribuyen mucho más allá del universo criminal. ${ }^{16}$ Notamos cuán enredados están los territorios urbanos supuestamente "criminales" con los "oficiales", con sus diversas características y estereotipos. El análisis nos permite abordar, por lo tanto, la importancia de la economía ilegal para el desarrollo económico de las ciudades del sur global... y más allá.

16 La vida cotidiana, las disposiciones de los actores y los recursos para construir la "ciudad desigual" son el marco conceptual central utilizado por Blokland (Blokland et al. 2016; Blokland 2017), con quienes he trabajado y de quienes aprendí un gran trato en los últimos años. Misse (2010) y L. Silva (2016) siguen un camino idéntico. También existe una "sociología del dinero" profundamente controvertida, que se remonta a Simmel (2004 [1900]) e incluye autores como Zelizer (1978, 1988, 1994, 2011), Hart (1973), Neiburg (2007) y Wilkis (2017). 


\section{BIBLIOGRAFÍA}

AGÊNCIA O GLOBO, 2019, "Renda média de mais da metade dos brasileiros é inferior a um salário mínimo”, Época Negócios. Disponible en < https://epocanegocios.globo.com/Bra sil/noticia/2019/10/renda-media-de-mais-da-metade-dos-brasileiros-e-inferior-um-sala rio-minimo.html > (última consultación en enero 2022).

ALMEIDA, Ronaldo de, 2019, "Bolsonaro presidente: conservadorismo, evangelismo e a crise brasileira", Novos Estudos CEBRAP, 38 (1): 185-213.

AMIT, Vered, y Caroline KNOWLES, 2017, "Improvising and navigating mobilities: tacking in everyday life", Theory, Culture \& Society, 34 (7-8): 165-179. Disponible en < https:// doi.org/10.1 177/0263276417724876 > (última consultación en enero 2022).

APPADURAI, Arjun, 1986, The Social Life of Things. Nueva York: Cambridge University Press. ARIAS, Enrique Desmond, y Nicholas BARNES, 2017, "Crime and plural orders in Rio de Janeiro, Brazil”, Current Sociology, 65 (3): 448-465.

BATISTA, Liniker Giamarim, 2015, A Grande Cidade e a Vida no Crime: Uma Etnografia dos Mercados do Crime em Uma Periferia de São Paulo. Campinas: Universidade Estadual de Campinas, disertación de posgrado en Antropologia Social.

BECKERT, Jens, y Matías DEWEY (orgs.), 2017, The Architecture of Illegal Markets: Towards an Economic Sociology of Illegality in the Economy. Oxford: Oxford University Press.

BERAlDO, Ana, 2020, Negociando a Vida e a Morte: Estado, Igreja e Crime em Uma Favela de Belo Horizonte. São Carlos: Universidade Federal de São Carlos, tesis de doctorado en Sociología.

BIONDI, Karina, 2018, Proibido Roubar na Quebrada: Território, Hierarquia e Lei no PCC. São Paulo: Terceiro Nome.

BLOKLAND, Talja, 2017, Community as Urban Practice. Cambridge: Polity Press.

BLOKLAND, Talja, Carlotta GIUSTOZZI, Daniela KRÜGER, y Hannah SCHILLING, 2016, Creating the Unequal City: The Exclusionary Consequences of Everyday Routines in Berlin. Berlin: Ashgate.

BOURDIEU, Pierre, 2013, “Espaço físico, espaço social e espaço físico apropriado”, Estudos Avançados, 27 (79): 133-144. Disponible en < https://doi.org/10.1590/S0103-401420130 $00300010>$ (última cosultación en enero 2022).

CAldeira, Teresa, 2000, Cidade de Muros: Crime, Segregação e Cidadania em São Paulo. São Paulo: EdUSP.

CAVALCANTI, Mariana, 2007, Of Shacks, Houses and Fortresses: An Ethnography of Favela Consolidation in Rio de Janeiro. Chicago: The University of Chicago Press.

CEFAÏ, Daniel, y Edouard GARDELLA, 201 1, L'urgence sociale en action: ethnographie du samusocial de Paris. Paris: La Découverte.

COHEN, Corentin, 2017, Politiques des images dans les conflits armés contemporains: cas de l'insurrection de Boko Haram et de la violence urbaine liée au Primeiro Comando da Capital à Sao Paulo. Paris: Ecole doctorale de Sciences Politiques, tesis de doctorado.

DAS, Veena, 2007, "In the region of rumor", in Veena Das, Life and Words: Violence and the Descent into the Ordinary. Berkeley, Los Angeles y Londres: University of California Press, 108-134.

DENNIS, Kingsley, y John URRY, 2009, After the Car. Polity Press.

DEWEY, Matías, 2015, El Orden Clandestino: Política, Fuerzas de Seguridad y Mercados Ilegales en la Argentina. Buenos Aires: Katz Editores. 
DEWEY, Matías, 2016, Porous Borders: The Study of Illegal Markets from a Sociological Perspective. MPIfG discussion paper, 16/2. Colonia: Max Planck Institute for the Study of Societies

FElTran, Gabriel de Santis, 201 1, Fronteiras de Tensão: Política e Violência nas Periferias de São Paulo. São Paulo: UNESP/CEM.

FELTRAN, Gabriel de Santis, 2014, "O valor dos pobres: a aposta no dinheiro como mediação para o conflito social contemporâneo”, Caderno CRH, 27 (72): 495-512.

FELTRAN, Gabriel de Santis, 2016, "La valeur des pauvres: le pari sur l'argent comme médiateur du conflit social contemporain”, Confins, 35 (28): 0-22. Disponible en < https://doi. org/10.4000/confins.11198 > (última consultación en enero 2022).

FElTrAN, Gabriel de Santis, 2018, Irmãos: Uma História do PCC. São Paulo: Companhia das Letras.

FELTRAN, Gabriel de Santis, 2019, “(Il)licit economies in Brazil: a ethnographic perspective”, Journal of Illicit Economies and Development, l (2): 145-154. Disponible en < https:// doi.org/10.31389/jied.28 > (última consultación en enero 2022).

FEltran, Gabriel de Santis, 2020, The Entangled City: Crime as Urban Fabric in São Paulo. Manchester: Manchester University Press.

FIESP - FEDERAÇÃO DAS INDÚSTRIAS DO ESTADO DE SÃO PAULO, 2017, Mercados Ilícitos Transnacionais em São Paulo, 2017: A Economia Criminal Transnacional. São Paulo: Federação das Indústrias do Estado de São Paulo.

FISCHER, Brodwyn, Brian MCCANN, y Javier AUYERO (orgs.), 2014, Cities from Scratch: Poverty and Informality in Urban Latin America. Durham y Londres: Duke University Press.

FREIRE-MEDEIROS, Bianca, 2009, "The favela and its touristic transits", Geoforum, 40 (4): 580-588.

FREIRE-MEDEIROS, Bianca, Vera da Silva TELLES, y Thiago ALLIS, 2018, "Por uma teoria social on the move", Tempo Social, 30 (2): 1-16.

FREIRE-MEDEIROS, Bianca, y Palloma Valle MENEZES, 2016, "As viagens da favela e a vida social dos suvenires", Sociedade e Estado, 31 (3): 65 1-670.

GOFFMAN, Erving, 2016, Frame Analysis: An Essay on the Organization of Experience. Boston: Northeastern University Press.

GRILlO, Carolina Christoph, 2013, Coisas da Vida no Crime: Tráfico e Roubo em Favelas Cariocas. Rio de Janeiro: Universidade Federal do Rio de Janeiro, tesis de doctorado.

GUYER, Jane I., (org.), 1995, Money Matters: Instability, Values and Social Payments in the Modern History of West African Communities. Londres: Heinemann.

GUYER, Jane I., 2004, Marginal Gains: Monetary Transactions in Atlantic Africa. Chicago: The University of Chicago Press.

HART, Keith, 1973, "Informal income opportunities and urban employment in Ghana", The Journal of Modern African Studies, 11 (1): 61-89.

HENARE, Amiria, Martin HOLBRAAD, y Sari WASTELl, 2007, "Introduction: thinking through things", Thinking through Things: Theorising Artefacts Ethnographically. Londres: Routledge, $11-31$.

HIRATA, Daniel Veloso, 2018, Sobreviver na Adversidade: Mercado e Formas de Vida. São Carlos: EdUFSCar.

HIRATA, Daniel Veloso, y Carolina Christoph GRILlO, 2017, “Sintonia e amizade entre patrões e donos de morro: perspectivas comparativas entre o comércio varejista de drogas em São Paulo e no Rio de Janeiro", Tempo Social, 29 (2): 75-98. 
HIRATA, Daniel Veloso, y Carolina Christoph GRILlO, 2019, "Crime, guerra e paz: dissenso político-cognitivo em tempos de extermínio”, Novos Estudos - CEBRAP, 38 (3): 553-571. HOLSTON, James, 2009, "Insurgent citizenship in an era of global urban peripheries", City \& Society, 21 (2): 245-267.

INVERSES COLLECTIF, 2016, "L'informalité politique en ville. 8 chercheurs et 9 villes face aux modes de gouvernement urbain", in Marie Morelle, Sébastien Jacquot, Jérôme Tadié, Nicolas Bautès, Claire Bénit-Gbaffou, Fabrizio Maccaglia, Jean Rivelois y Alexis Sierra, L'Espace politique, 29 (2016-2). Disponible en < http://journals.openedition.org/ espacepolitique/3806 > (última consultación en enero 2022).

KESSLER, Gabriel, 2011 , "La extensión del sentimiento de inseguridad en América Latina: relatos, acciones y políticas en el caso argentino”, Revista de Sociologia e Politica, 19 (40): 83-100.

KNOWLES, Caroline, 2014, Flip-Flop: A Journey through Globalisation's Backroads. Londres: Pluto Press.

KNOWLES, Caroline, 2015, “The flip-flop trail and fragile globalization”, Theory, Culture \& Society, 32 (7-8): 231-244.

KOPYTOFF, Igor, 2014, "The cultural biografy of things: comoditization as process", The Social Life of Things. Cambridge: Cambridge University Press, 63-91.

LASCOUMES, Pierre, y Patrick LE GALÈS, 2012, Sociologie de l'action publique. Paris: Armand Colin (2. ${ }^{\mathrm{a}}$ edición).

LATOUR, Bruno, 2005, Reassembling the Social: An Introduction to Actor-Network Theory. Oxford: Oxford University Press.

LYRA, Diogo, 2013, A República dos Meninos: Juventude, Tráfico e Virtude. Rio de Janeiro: Mauad X/FAPERJ.

MALDONADO, Janaina, 2020, Jogando Meu Corpo no Mundo: Relações entre Conflito Urbano e Diferença. São Carlos: Universidad Federal de São Carlos, disertación de máster en Sociología.

MANSO, Bruno, y Camila Caldeira Nunes DIAS, 2018, A Guerra: A Ascensão do PCC e o Mundo do Crime no Brasil. São Paulo: Todavia.

MARTINS JR., Angelo, 2015, Lives in Motion: Notebooks of an Immigrant in London. Londres: Whyte Tracks.

MATTOS, Carla dos Santos, 2017, "O funk proibido como política de integração marginal”, in Giordano B. Bertelli y Gabriel Feltran, Vozes à Margem: Periferias, Estética e Política. São Carlos: EdUFSCar, 65-84.

MILlER, Daniel, 2001, Car Cultures. Bloomsbury, RU: Bloomsbury Academic (1. a edición). MINTZ, Sidney, 2003, O Poder Amargo do Açúcar: Produtores Escravizados, Consumidores Proletarizados. Recife: UFPE.

MISSE, Michel, 2005, O Delito como Parte do Mercado Informal, seminario internacional "A Violência na América Latina". Berlin: Freie Universitat.

MISSE, Michel, 2010, "Crime, sujeito e sujeição criminal: aspectos de uma contribuição analítica sobre a categoria "bandido" ", Lua Nova, 79: 15-38. Disponible en < https:// doi.org/10.1590/s0102-64452010000100003 > (última consultación en enero 2022).

MISSE, Michel, 2018, "Violence, criminal subjection and political merchandise in Brazil: an overview from Rio", International Journal of Criminology and Sociology, 7: 135-148. Disponible en < https://doi.org/10.6000/1929-4409.2018.07.09> (última consultación en enero 2022). 
NEIBURG, Federico, 2007, "As moedas doentes, os números públicos e a antropologia do dinheiro", Mana, 13 (1): 119-151.

PINHO, Isabela Vianna, Gregório ZAMBON, y Lucas Alves Fernandes SILVA, 2021 , "Dismantling a stolen car", in Gabriel Feltran (org.), Stolen Cars: A Journey through São Paulo's Urban Conflict. Hoboken, NJ: John Wiley \& Sons, 127-147.

RABOSSI, Fernando, 2008, "En la ruta de las confecciones", Crítica en Desarrollo, 2: 151-171. RABOSSI, Fernando, 2011, "Negociações, associações e monopólios: a política da rua em Ciudad del Este (Paraguai)", Etnográfica, 15 (1): 83-107.

RABOSSI, Fernando, 2015, "Tempo e movimento em um mercado de fronteira: Ciudad del Este, Paraguai", Sociologia \& Antropologia, 5 (2): 405-434. Disponible en < https://doi. org/10.1590/2238-38752015v523 > (última consultación en enero 2022).

RABOSSI, Fernando, 2018, "Smuggling realities: on numbers, borders, and performances”, HAU: Journal of Ethnographic Theory, 8 (1-2): 265-281. Disponible en < https://doi. org/10.1086/698218 > (última consultación en enero 2022).

REDE BRASIL ATUAL, 2019, "Mapa da desigualdade: morador de bairro rico vive até 23 anos mais que na periferia paulistana”. São Paulo: Rede Brasil Atual. Disponível en $<$ https://www.redebrasilatual.com.br/cidadania/2019/1 1/mapa-da-desigualdade-23anos/ > (última consultación en enero 2022).

REQUENA, Carolina, 2019, A Política da Infraestrutura Metropolitana no Brasil: Governança de Obras de Mobilidade Urbana em Perspectiva Comparada (Tentativo). São Paulo: Universidade Estadual de São Paulo, tese de doutorado.

SANDOVAL HERNÁNDEZ, Efrén, 2005, "Pobreza, marginación y desigualdad en Monterrey: puntos de partida", Frontera Norte, 17 (33): 133-141.

SANDOVAL HERNANDÉZ, Efrén, 2008, "Estudios sobre pobreza, marginación y desigualdad en Monterrey", Papeles de Población, 14 (57): 169-191.

SANDOVAL HERNÁNDEZ, Efrén, 2012, "Economía de la fayuca y del narcotráfico en el noreste de México: extorsiones, contubernios y solidaridades en las economías transfronterizas", Desacatos: Revista de Ciencias Sociales, 98: 43-60.

SILVA, José Douglas dos Santos, 2017, Políticas de Quebrada e Políticas Estatais Referentes aos Homicídios em Luzia, São Paulo. São Carlos: Universidade Federal de São Carlos, tesis de máster en Sociología.

SILVA, Luis Antonio Machado da, 2008, Vida sob Cerco: Violência e Rotina nas Favelas do Rio de Janeiro. Rio de Janeiro: Nova Fronteira.

SILVA, Luis Antonio Machado da, 2010, “'Violência urbana', segurança pública e favelas: o caso do Rio de Janeiro atual”, Caderno CRH, 23 (59): 283-300.

SILVA, Luis Antonio Machado da, 2016, Fazendo a Cidade: Trabalho, Moradia e Vida Local entre as Camadas Populares Urbanas. Rio de Janeiro: Mórula Editorial.

SILVA, Marcella de Araújo, 2017, "Houses, tranquility and progress in an Área de Milícia", Vibrant: Virtual Brazilian Anthropology, 14 (3): 132-148. Disponible en < https://doi. org/10.1590/1809-43412017v14n3p132 > (última consultación en enero 2022).

SIMMEL, Georg, 2004 [1900], The Philosophy of Money. Londres: Routledge. Disponible en < https://doi.org/10.5840/philhist 1991241/222 > (última consultación en enero 2022).

SIMMEL, Georg, 2010, The View of Life: Four Metaphysical Essays with Journal Aphorisms. Chicago y Londres: The University of Chicago Press.

SIMONE, Abdoumaliq, 2004, "People as infrastructure: intersecting fragmentes in Johannesburg”, Public Culture, 16 (3): 407-429. 
TELles, Vera da Silva, 2010, A Cidade nas Fronteiras do Legal e Ilegal. São Paulo: Argumentum.

TELLES, Vera da Silva, 2013, "Prospectando a cidade a partir de suas margens: notas inconclusas sobre uma experiência etnográfica", Contemporânea, 3 (2): 359-373.

TILlY, Charles, 1998, Durable Inequality. Berkeley, Los Angeles y Londres: University of California Press.

TSING, Anna Lowenhaupt, 2005, Friction: An Ethnography of Global Connection. Princeton y Oxford: Princeton University Press.

TSING, Anna Lowenhaupt, 2015, The Mushroom at the End of the World: On the Possibility of Life in Capitalist Ruins. Princeton: Princeton University Press.

URRY, John, 2002, "Mobility and proximity", Sociology, 36 (2): 255-274.

URRY, John, 2004, “The 'system' of automobility”, Theory, Culture \& Society, 21 (4-5): 25-39.

URRY, John, 2010, “Mobile sociology”, British Journal of Sociology, 61 (s 1): 347-366.

WACQUANT, Loïc, 1996, "The rise of advanced marginality: notes on its nature and implications", Acta Sociologica, 39: 121-39.

WACQUANT, Loïc, 2009, Prison of Poverty. Minneapolis: University of Minnesota Press.

WACQUANT, Loïc, y John HOWE, 2008, Urban Outcasts. Cambridge: Polity Press.

WHYTE, William Foote, 2005, "A estrutura social do gangsterismo", in William Foote Whyte, Sociedade de Esquina: A Estrutura Social de Uma Área Urbana Pobre e Degradada. Rio de Janeiro: Editora Zahar, 129-162.

WILKIS, Ariel, 2017, The Moral Power of Money: Morality and Economy in the Life of the Poor. Stanford, CA: Stanford University Press.

WILlIS, Graham Denyer, 2015, The Killing Consensus: Police, Organized Crime, and the Regulation of Life and Death in Urban Brazil. Oakland, CA: University of California Press.

ZELIZER, Viviana, 1978, "Human values and the market: the case of life insurance and death in 19th-century America”, American Journal of Sociology, 84 (3): 591-610.

ZELIZER, Viviana, 1988, "Establishing a theoretical and empirical agenda", Sociological Forum, 3 (4): 614-634.

ZELIZER, Viviana, 1994, The Social Meaning of Money. Princeton: Princeton University Press. ZELIZER, Viviana, 201 1, Economic Lives: How Culture Shapes the Economy. Princeton: Princeton University Press. 